\title{
The Association of Clinical Pathologists: 69th Meeting
}

The sixty-ninth general meeting of the Association of Clinical Pathologists was held at the Roya $\mathbb{\mathbb { B }}$ College of Surgeons, London, on 27, 28, and 29 September 1962. At this meeting two symposia were held, one on laboratory planning and design and the other on bone metabolism (jointly with 5 the Association of Clinical Biochemists). This will be published as a monograph. Abstracts of theother papers read at the meeting follow.

The Presidential address on 'The pathologist and his writings was given by A. GORDON SIGNY An abridged version of the address will be published in The British Medical Journal.

\section{DEVELOPING A REAGENT FOR ESTIMATING FACTORS AFFECTED BY COUMARIN DRUGS}

F. NOUR-ELDIN (Bristol) first outlined briefly the relationship between the blood-clotting activity of tissue extracts and blood coagulation in vivo, advancing evidence suggesting the separate existence of tissue clotting factors, but no thromboplastic activity, during life. He then discussed the composition of the reagents used in the control of coumarin therapy and reported his attempts to develop a reagent suitable for the collective estimation of factors II, VII, IX, and X. Several methods were tried in order to remove factor IX from tissues and to obtain a tissue extract or a reagent free of factors affected by coumarin drugs. These experiments led to two main findings.

1 For the control of coumarin therapy, a properly prepared extract of acetone-dried bovine brain alone $(0.6 \mathrm{~g} . / 10 \mathrm{ml}$. phenol saline) provides an excellent substitute for the more expensive and elaborate Thrombotest. Like the latter, however, it is insensitive to variations in the levels of factor IX.

2 The sensitivity to factor IX of an artificially constructed reagent free of factors II, VII, IX, and X was tested. It was considered too low to be of practical value. In addition, this reagent had the drawback of being difficult to prepare and preserve.

\section{DYSHAEMOPOIESIS IN APLASTIC ANAEMIA}

S. M. LEWIS (Postgraduate Medical School, London) reported investigations in 45 patients with aplastic anaemia. They ranged in age from 2 to 72 years with approximately equal numbers of each sex. Contrary to traditionally accepted criteria, two-thirds of the patients had reticulocyte counts greater than $2 \%$ at some stage of their illness, in 12 patients it was more than $5 \%$, and the count reached a maximum of $13 \%$ in one case. Further, in the majority of cases the red cells showed morphological abnormalities which ranged from anisocytosis and slight macrocytosis to marked poikilocytosis, elliptocytosis, and cell fragmentation.

Red-cell survival studies were performed by the ${ }^{51} \mathrm{Cr}$ method on 17 patients, and in 15 there was an increased rate of elimination of the labelled cells from the circula $f$ tion. This appeared to be due, essentially, to haemolysis? and in only two instances could it be accounted forentirely or partly by haemorrhage.

The presence of an intrinsic red cell defect was also demonstrated by the reaction of the cells to a high-titren cold-antibody serum. The red cells of aplastic anaemia showed the same sensitivity to lysis by the serum as those of severe untreated megaloblastic anaemias and myeloo proliferative diseases, but less than P.N.H. cells. It is thought that this test is a non-specific index of abnormal-O ity of red cells occurring as a sequel to pathologicak erythropoiesis. There was no definite quantitative rela tionship between the intensity of lysis, the life span in vivo, and the degree of morphological abnormality. TheD exact nature and the cause of the qualitative defect of red? cells in aplastic anaemia remains obscure.

\section{TRANSFER OF STORAGE IRON TO ERYTHROBLASTS IN THE BONE MARROW}

MARY D. SMITH (Glasgow) said that in sternal marrow smears from a patient with chloramphenicol aplasia it was observed that iron was accumulated in excess in the aplastic areas, but was completely absent from cellulae foci in the same smears. In these sites erythropoiesis was hyperactive and apparently represented areas of com? pensatory or regenerative erythropoiesis. In the later phases, failure supervened and iron began to accumulate also in the remaining cellular areas.

The only explanation for the observations seemed to bes local utilization of iron by erythroblasts in the hyper $N$ plastic foci and the suggestion was made that the features represent cytological evidence of Bessis' electron microsw scope studies ${ }^{1}$ in which he observed that erythroblast acquire iron granules for haemoglobin synthesis directlyo from reticulo-endothelial storage cells by the process of 'ropheocytosis'. (The term is derived from the Greek? 'I aspirate'.)

Further study of these and other preparations of marrow smears stained for iron seemed to show a gradua transition of the iron in storage cells from a compace्ष

${ }^{1}$ Comptes rendus des séances de la Société de Biologie (1956), 11, 1903ర్ 
granular form in a rounded cell to a diffuse form throughout the cell body which itself develops iron-filled pseudopodial extensions. The latter can be seen in apposition with red cell precursors and at this stage Bessis describes the direct transfer of iron from the central reticuloendothelial cell to the erythroblasts. The transition from granular to diffuse staining probably correlates with the variable grouping or dispersion of iron granules which Bessis comments upon.

Serial lantern slides from marrow smears stained by May-Grünwald and Prussian blue methods taken in conjunction with Bessis' diagrams illustrated these features.

\section{FEATURES OF THE AUTOANALYZER IN THE HOSPITAL LABORATORY}

M. BENTON, JANET MCNAIR, D. A. PODMORE, and A. JORDAN (Sheffield) reported that pooled horse serum allows comparison of the standard deviations of different determinations derived from bench methods with those derived from the Autoanalyzer. Results are satisfactory. Contamination from previous high (or low) results affects the next result, e.g., $1 \mathrm{mg} . / 100 \mathrm{ml}$. for every $15 \mathrm{mg} . / 100 \mathrm{ml}$. difference for the blood urea. With a Dexion trolley the Autoanalyzer is taken down to the diabetic clinic where determinations at 60 per hour have a standard deviation of $\pm 9 \mathrm{mg} . / 100 \mathrm{ml}$. A double crook and two pumps allows the simultaneous determination of sodium, potassium, chloride, bicarbonate and urea. Repeated standards during runs to check drift and control sera for each batch are important.

\section{MALIGNANCY IN SCARS, CHRONIC ULCERS, AND SINUSES}

A. H. CRUICKSHANK, E. MAVIS MCCONNELl (Liverpool), and D. G. MILLER (Warrington) described a series of 44 cases of malignancy in scars, chronic sinuses, and ulcers which included the following predisposing lesions: a 20-yearold sinus from ischial bursitis, a 23-year-old bed sore, a congenital gumma about 50 years old, three burn scars (average age of scar 56.3 years), 11 sinuses from chronic osteomyelitis, and 27 chronic ulcers of the leg. The osteomyelitis cases included two rapidly fatal sarcomas, one in a sinus present for 16 years, the other in a 20 -year-old sinus. The remaining tumours in this group were squamous carcinomas and the average age of the sinus was $37 \cdot 1$ years.

In the cases of varicose ulcer, the ulcer had been present, on the average, for 21 years before the onset of malignancy. One case in this group, with an ulcer not known to be more than five years old, developed a sarcoma that was fatal in six months.

The biopsy specimens of the 44 cases were reviewed. They were difficult to interpret in 17 cases, including one of the cases of sarcoma. The difficulty was greatest in osteomyelitis.

It was pointed out that, though the conditions discussed are now known as Marjolin's ulcer, Marjolin did not regard the warty ulcers that he described in 1828 as malignant. It was R. W. Smith in 1850 who identified cancers in scars with the warty ulcers of Marjolin, and DaCosta in 1903 who used the name Marjolin's ulcer for cases of malignant transformation in previously simple chronic ulcers of the leg.

IN VITRO 131-I-TRIIODOTHYRONINE BINDING TO ERYTHROCYTES AS AN INDEX OF THYROID FUNCTION

H. G. MORGAN, D. G. ADAMSON, and K. SZÀz said that the percentage uptake by erythrocytes of ${ }^{131}$ I-triiodothyronine $\left(\mathrm{T}_{3}\right)$ added in vitro to whole blood was an indirect measure of plasma thyroxine $\left(T_{4}\right)$ concentration and of thyroxine-binding-protein capacity, and thus of thyroid function (Hamolsky, 1957). The red cell uptake is increased in hyperthyroidism and reduced in hypothyroidism, but is also altered by other conditions, including pregnancy, uraemia, anticoagulant therapy, and nephrosis.

The technique involves measurement of whole blood radioactivity after incubation with labelled triiodothyronine and then that of the washed red cells. Results are expressed as percentage red cell uptake corrected for haematocrit, or as the binding coefficient, ' $K$ ', of Adams (1960). The volume, frequency, duration, and temperature of washing are critical, and must be standardized. A constant weight of $\mathrm{T}_{3}$ was used, $9 \mathrm{~m} \mu \mathrm{g}$. per $3 \mathrm{ml}$. blood, since larger amounts caused an increase in red cell uptake. Dilution of $\mathrm{T}_{3}$ from stock must be fresh; steadily increasing uptakes with a dilute solution over eight weeks were found, to a maximum of $35 \%$ red cell uptake, but a fresh dilution of the original stock solution still gave normal values. These results were not due to radioactive iodide or thyroxine, but possibly to other decomposition products such as di-iodothyronine.

'Normal' values were from 13 to $21 \%$ of corrected red cell uptake. Six of 27 'thyrotoxic', three of 23 'hypothyroid', and 44 of 56 'euthyroid' patients gave results within these limits. Results were also useful in assessing therapy. Thirty-two of $\mathbf{4 4}$ pregnant patients gave results in the apparently 'hypothyroid' range, and were independent of the duration of pregnancy.

This test is not sufficiently reliable for routine use as a single test of function, but can be used even after iodide administration and avoids the administration of radioactive substances to patients.

\section{REFERENCES}

Adams, R. (1960). J. clin. Endocrinol., 20, 1366.

Hamolsky, M. W. (1957). J. clin. Endocrinol., 17, 33.

\section{THE USE OF ${ }^{132} \mathrm{~L}$ IN THE DIAGNOSIS OF BORDERLINE} THYROTOXICOSIS AND MYXOEDEMA

J. R. HOBBS (Westminster) Radioiodine studies are mainly required in borderline cases, and here the need for repeat tests after triiodothyronine $\left(\mathrm{T}_{3}\right)$ and thyroidstimulating hormone (T.S.H.) gives ${ }^{132} 1$ a definite advantage over ${ }^{131}$, both on account of radiation hazards and of the negligible background errors.

The described four-hour ${ }^{132} 1$ neck uptake was remarkably constant in a given individual with narrow limits of reproducibility (coeff. variation $=3.5 \%$ ).

Some $10 \%$ of thyrotoxicosis was classified as borderline and absence of $T_{3}$ suppression as defined using $\left.{ }^{132}\right]$ 
(no change outside reproducible limits after six days of $\mathrm{T}_{3}$ at $40 \mu \mathrm{g}$. eight-hourly) was found to be virtually diagnostic in 29 borderline patients, in nine of whom the four-hour uptake was within the normal limits (11-31\% of dose).

Some $40 \%$ of myxoedema was classified as borderline and no thyroid reserve as defined using ${ }^{132}$ l (no change outside reproducible limits after $3 \times 2 \cdot 5$ i.u. T.S.H. intramuscularly daily) was found to be virtually diagnostic in 16 borderline patients in whom the four-hour uptake was within normal limits.

${ }^{132} 1$ permits easy daily measurements and a stepwise response observed after T.S.H. (e.g., $12 \rightarrow 19 \rightarrow 34 \rightarrow 46 \%$ of dose) was of diagnostic help in three patients with hypopituitarism, in whom the initial four-hour uptake was within normal limits.

${ }^{132} 1$ provides a practical and desirable alternative to $\left.{ }^{131}\right]$ in routine diagnosis.

\section{PLASMA INSULIN ASSAYS IN INSULINOMA}

ELLIS SAMOLS and VINCENT MARKS (Epsom) described an immuno-assay technique used to study plasma insulin levels in 12 patients with proven insulinomas. Samples for assay were taken on a number of different days during fasting hypoglycaemia. In 11 patients high fasting plasma insulin levels were found on one or more days, but in eight of these there were other occasions when fasting plasma insulins were normal. The twelfth patient had a normal fasting insulin on three occasions. When samples were taken at 15 to 30 -minute intervals in two fasting patients, there was a large spontaneous fluctuation in plasma insulin levels. The fluctuations, which do not occur in normal subjects, complicate interpretation of the effects of various substances on plasma insulin in patients with insulinomas.

Intravenous tolbutamide produced an exaggerated rise in plasma insulin in each of the five patients examined. Glucose-induced hyperglycaemia was associated with a normal insulin response in three patients but no apparent response in two. Elevation of blood glucose after glucagon was accompanied by an increase in plasma insulin but the rise in insulin was excessive in only one of the three patients tested. The oral administration of leucine to four patients was followed by a marked rise in plasma insulin. When the test was repeated on two of these patients after surgical removal of the tumour, the plasma insulin response to leucine was normal.

A high fasting plasma insulin level associated with hypoglycaemia strongly supports the diagnosis of an insulinoma but is not pathognomonic. A normal fasting plasma insulin does not exclude the presence of an insulinoma.

J. SCHRAGER (Wigan) reported an attempt made in his laboratory to study the carbohydrate components of human gastric mucopolysaccharides.
A chromatographic investigation yielded results to be reported elsewhere. The procedure of the fractional $\underline{2}$ aspirations of the gastric secretion had previously been :described.

Adequate quantities for routine investigations were removed from each aspirated specimen; the remaining secretions were pooled and treated with diastase (total hexose:diastase $=1: 20$ by weight) at $37^{\circ} \mathrm{C}$. for five hours $\frac{\rho}{T}$

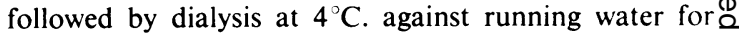
three days and distilled water until chloride free. The dialyzed secretion was concentrated under reduced pressure at $25^{\circ} \mathrm{C}$. to about $1 / 20$ th of its volume and hydrolized. with $2 \mathrm{NH}_{2} \mathrm{SO}_{4}$ at $100^{\circ} \mathrm{C}$. for 2 hours in sealed ampoules. $\overrightarrow{\vec{\omega}}$ The hydrolysate was neutralized with $\mathrm{Ba}(\mathrm{OH})_{2}$, centrifuged, the supernatant evaporated to dryness in vacuo, and redissolved in the smallest quantity of water.? Whatman No. $118 \times 22.5$ in., descending development $\vec{\sigma}$ in 1-butanol pyridine water $(4: 6: 2)$ was used. Threedescending runs were made each time for 16 hours. The paper was dried, replaced in fresh solvent for each run응 and developed with aniline hydrogen phthalate reagent.

At least $200 \mathrm{ml}$. of gastric secretions is needed in order $\vec{c}$ to obtain the concentration of the individual sugars necessary for chromatography.

The gastric secretion of 20 volunteers, 40 patients with duodenal ulcers, 15 patients with gastric ulcers, and $12=$ patients with carcinoma of the stomach were investigated.

Results do not support the well-established assumptioncw that the human gastric mucopolysaccharides contain uronic acid. Gastric secretions were divided into two aliquot portions $\mathbf{A}$ and $\mathbf{B}$, glucuronic acid was added to portion B (final concentration $1 \%$ ). Gastric secretions $A$ 命 and $B$ and $1 \%$ chondroitin sulphate were treated as응 described above, hydrolysed and chromatographed.气 Uronic acid appeared in the chromatogram of the hydrolysate of gastric secretion $B$ as well as in that of chondroitin sulphate but none was present in the chro-? matogram of the hydrolysate of the gastric secretion $A \frac{7}{0}$

Our investigation shows that both glucose and mannose are present in all the chromatographed gastric secretions? The identification of glucose is based on the identity of the RF value given with glucose standards. It disappears. in chromatograms of gastric secretion hydrolysate incubated with glucose oxidase. Addition of glucose to the hydrolysate results in the intensification of the spots but not in the appearance of further ones.

The carbohydrate components of the gastric mucopoly saccharides of patients with carcinoma of the stomach show quantitative ratio differences from those of all othern gastric secretions investigated. In the latter galactose and fucose are the predominant sugars.

The secretion of the malignant stomach showed of marked decrease in galactose and a great increase in glucose, the galactose being often reduced to a mere trace.

The quantitative relationship of the carbohydrate components of the gastric mucopolysaccharides is being further investigated. 